\title{
ROD MILL MODERNIZATION AT ONESTEEL LAVERTON FOR INCREASED PRODUCTIVITY, UTILIZATION AND PRODUCT QUALITY*
}

Shanti Arangala ${ }^{1}$ Mohamed Ahmed ${ }^{2}$ Bruce V. Kiefer ${ }^{3}$

\begin{abstract}
Several improvements were made to the single strand rod mill at Laverton to increase production, reduce maintenance and improve several aspects of product quality. With changes to the water cooling line and control system, cobbles could be significantly reduced, more consistent properties obtained and yield improved. An upgrade of the laying head enabled vibrations to be reduced and thus allowed for higher speeds on small sizes. With potential for dramatically increased pipe life, a new pipe support and laying pipe system provided for improved laying pattern on small sizes and thus more uniform cooling on the conveyor and better coil package. This paper discusses details of these equipment and control system upgrades and the resulting benefits that have been realized from the project.
\end{abstract}

Keywords: Modernization; Laying head; Cooling; Coils.

Rolling Mills Operations Superintendent, OneSteel Market Mills, Laverton, Victoria, Australia.

2 Sales Manager, Primetals Technologies USA LLC Long Rolling, Worcester, Massachusetts, USA.

3 Principal Engineer, Primetals Technologies USA LLC Long Rolling, Worcester, Massachusetts, USA. 


\section{INTRODUCTION}

The wire rod mill at Laverton started in 1988 as an outlet to an existing bar mill, with the addition of two cantilevered stands and a 10-stand finishing block to roll wire rod. Other equipment in the outlet layout included water boxes, a pinch roll, laying head, cooling conveyor and vertical finishing end. A major modernization project in 1996 enabled the rod mill to operate independently of the bar mill, with the installation of a walking hearth furnace, six roughing stands, six intermediate stands and four prefinishing stands - all with a cantilevered design. No other significant changes were made to the rolling mill until 2008, when a project to increase mill speed was undertaken with the addition of a Morgan Pinch Roll and Morgan High Speed Laying Head. Further improvements in mill speed and processing capability were made possible with the 2014 installation of new water cooling boxes after the finishing block and upgrade of the laying head.

\section{MATERIAL AND METHODS}

\subsection{Reasons for Modernization}

OneSteel experienced repeated problems with the existing outdated cooling line. They sought an upgrade solution to improve mill utilization by increasing production speeds on small sizes, eliminate cobbles in the cooling line, and improve yield, coil package and product quality, and turned to Primetals Technologies (formerly Morgan Construction Company), the leader of high speed wire rod mills, and other suppliers to study the situation and make recommendations. During the first months following their inquiry, they visited some reference plants to see first-hand each supplier's proposed solution.

Given the study results, OneSteel set out to modernize their one-strand rolling mill by focusing on:

- Eliminating or significantly reducing cobbles in the cooling line after the rod block

- Increasing rolling speeds for small sizes

- Improving cooling and coil pattern on the cooling conveyor to increase final wire rod technical parameters

- Reducing uncooled front and tail rings to improve yield

- Improving laying head pipe life to reduce pipe change time and improve utilization

- Providing greater mill flexibility and better time utilization during size changes in the water cooling line

- Improving coil packages

- Reducing coil height.

\subsection{Key Modernization Elements}

In order to achieve all of the production and quality goals set for the mill modernization, OneSteel completely replaced the mill area between the rod block and laying head and upgraded the laying head with the latest SR Series ${ }^{\circ}$ pipe technology. 


\subsubsection{Morgan Water Boxes and Equalization Troughs}

With this project's focus on productivity and quality improvement, the length and placement of the water cooling boxes were important considerations. Detailed studies were undertaken of expected temperature profiles through the rolling line, alternative box placements and lengths for the entire product size range and all grades planned for the product mix.

At the exit of the existing rod block, a new breakout box was installed, then three new traversing water boxes were positioned to allow for excellent alignment of the rolling line from the rod block through to the laying head. New equalization troughs were also provided in the rolling line from the rod block to the laying head.

All of the new water boxes and equalization trough segments used the proven split bore design, with stainless steel investment cast parts for high wear resistance and reliable performance. Because of the importance of alignment to the success of continuous high speed rolling, the nozzles and troughs were located on machined stainless steel pads and headers to provide for accurate positioning during changes and to minimize any effects of thermal expansion. Figure 1 shows a traversing water box with covers opened for access to the split bore nozzles.

The traversing arrangements of the water boxes and troughs were implemented to enable quick size changes and reduce injury risk to the operators while lifting the old heavy cooling line sections. The new split design also limited the different bore sizes from 4 to 2 .

In conjunction with the new water boxes, a temperature control system was installed for closed-loop control of each cooling zone. Using a modularized system of valves and sensors for each water box, the flows and pressures could be monitored and regulated in each zone so that temperature could be controlled throughout the process.

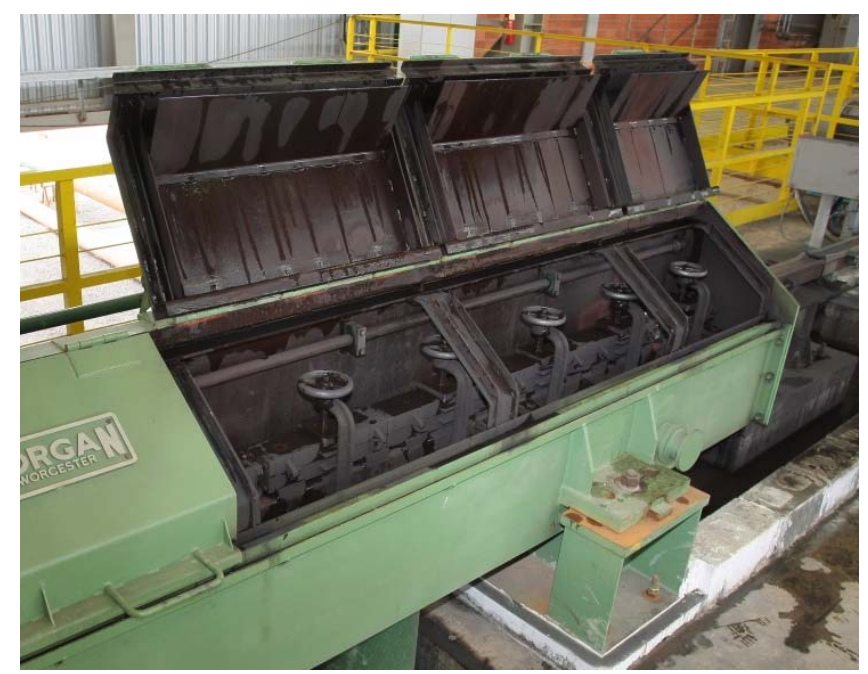

Figure 1 - Morgan Water Boxes

The new mechatronic automation system provided superior temperature control with $+/-10^{\circ} \mathrm{C}$ tolerance and enhanced the yield by minimizing the number of uncooled rings to only two or three.

In order to achieve all of the production and quality goals set for the mill modernization, OneSteel completely replaced the mill area between the rod block and laying head and upgraded the laying head with the latest SR Series ${ }^{\circledR}$ pipe technology. 


\subsubsection{Pinch Roll and Laying Head}

To increase actual operating speeds over the full size range and to produce a consistent ring pattern for uniformity of cooling and coil formation, the modernization included the installation of the latest laying head pipe support design.

For the most critical element in the high-speed operation, the Morgan High Speed Laying Head (Figure 2) was upgraded. This unit uses a novel design of integral pipe support, with the patented tail end control deflector with segmented trough. Included as part of the new laying head technology are SR Series laying head pipes, which produce consistent ring patterns at high speeds, and extend pipe life when compared with conventional pipes as a result of the patented self-regenerating pipe design [1].

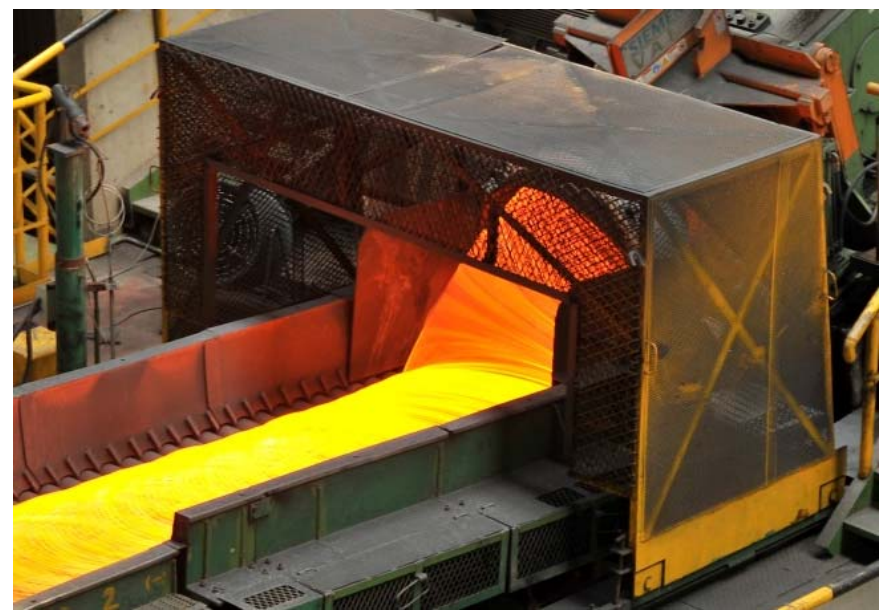

Figure 2 - Morgan High Speed Laying Head

\subsection{Mill Upgrade Implementation}

OneSteel and Primetals signed a contract to modernize the mill in November 2013 with the scope of all the above-mentioned equipment. Project execution was tailored to minimize changes to the interface points of installations and reduce the shutdown time by preassembly and pre-alignment of equipment. On-time equipment delivery meant that the mill was ready to roll in December 2014. Figure 3 shows a schematic of the equipment arrangement in the modernized area of the wire rod mill. Figure 4 shows a view of the water cooling line after the modernization.

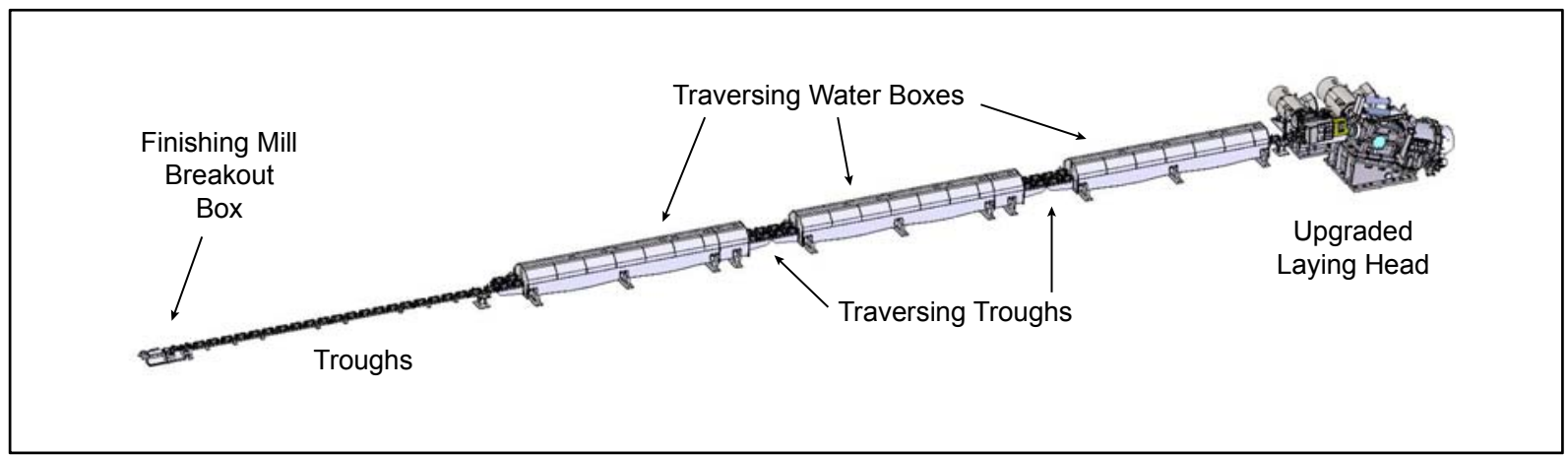

Figure 3 - Equipment arrangement after modernization. 


\subsection{Startup}

The first billet was rolled on 9 December 2014, and within the first few days of operation the mill met its production target. There were no cobbles related to the upgrade project. In current market conditions, production delays can be extremely costly. This type of rapid startup can only be accomplished with a proven technology such as the Morgan Water Boxes and Morgan High Speed Laying Head, along with an expert commissioning team.

\section{PERFORMANCE AND RESULTS}

After a successful startup, some dramatic improvements on certain aspects of goals of the project quickly became apparent.

The production speeds on small sizes were increased due to a number of factors:

- Improved laying head pattern

- Improved shape of front ends and tail ends with the SR Series pipe technology

- Better design of the water cooling elements

- Enhanced temperature control integrated mechatronic automation package, which made high speed and high performance pressure and flow control possible in the cooling water valve arrangements.

Figure 5 below shows the speed improvements (in $\mathrm{m} / \mathrm{s}$ ) on the small size products, which benefitted most from the upgrade.

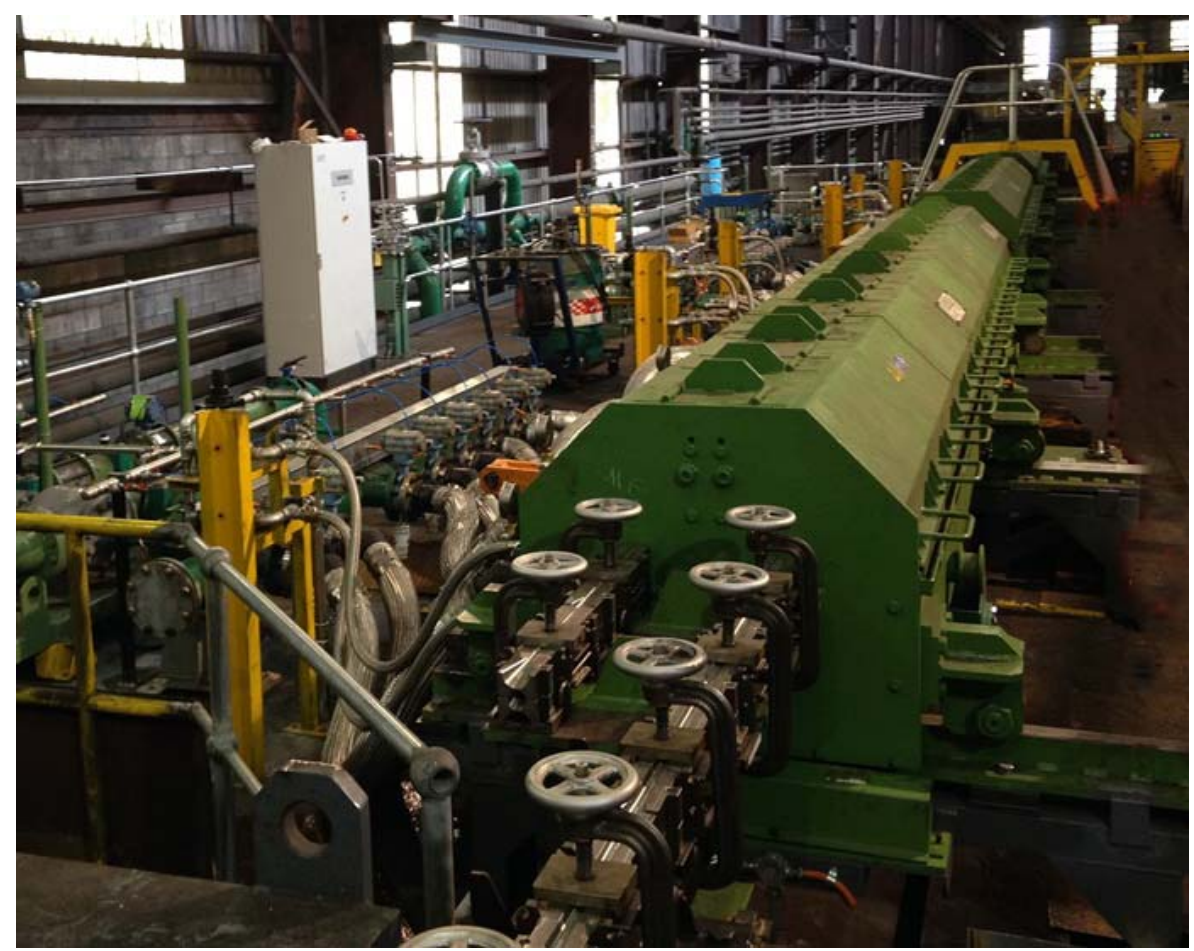

Figure 4 - Water box area after modernization 


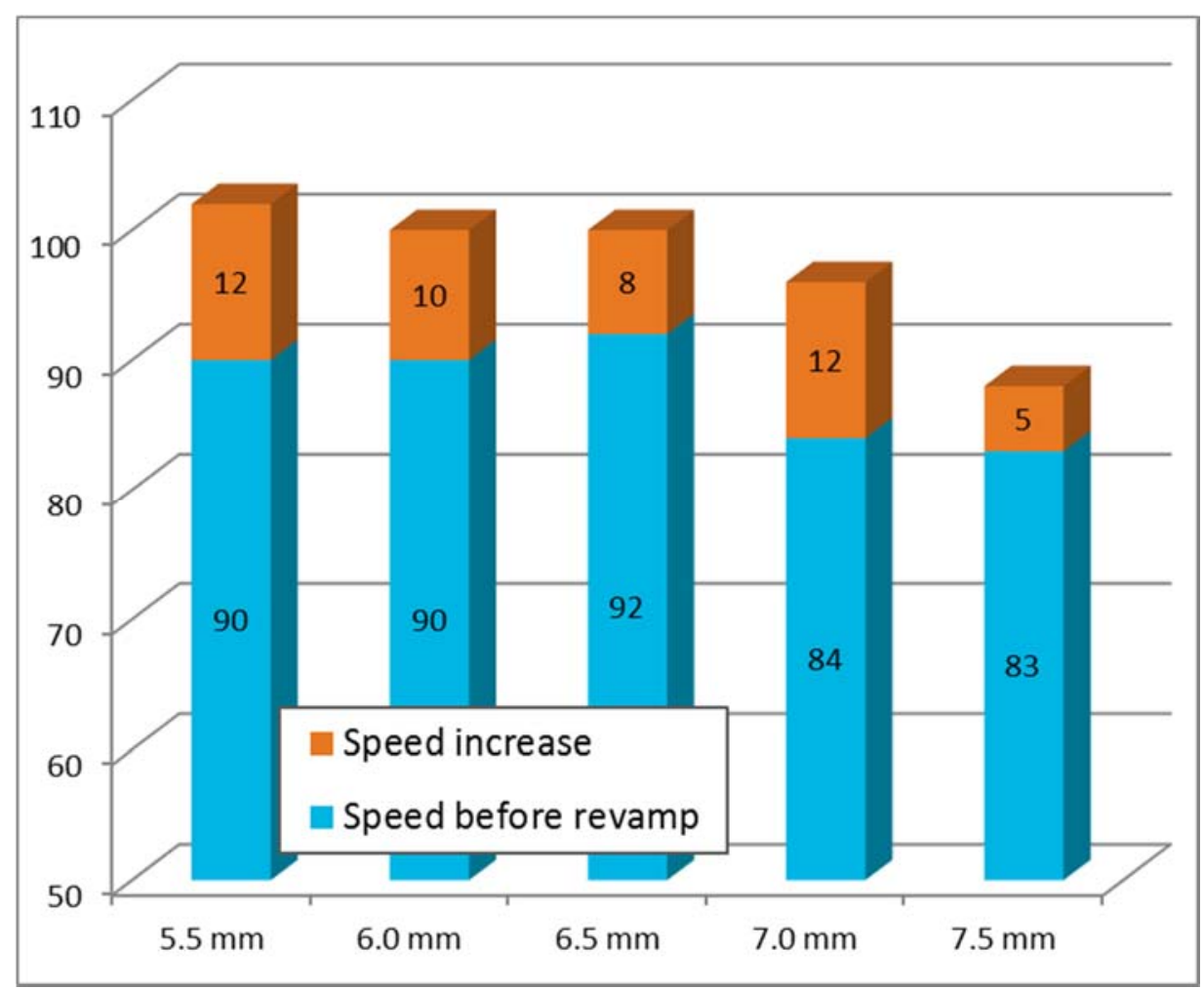

Figure 5 - Increased finishing speed capability.

The laying head pipe life with the new SR Series technology has increased from an average of 11,500 tons to an estimated minimum of 60,000 tons, reducing production time lost to frequent laying head pipe changes. This is a significant improvement, particularly with the higher finishing speeds on the small diameter products.

The yield was improved by reducing cobbles in the cooling line during small size rolling from an average of three cobbles per week to no reported cobbles at all. As of this writing, no cobbles have occurred due to cooling line problems since the project startup. The yield has also improved by reducing front end and tail end uncooled rings from a previous 6 to 12 rings down to 2 to 3 rings, due to optimization in the mechatronic automation package.

Mill utilization was improved by reducing the number of cooling line nozzle replacement cycles from four sizes to two sizes. Also, by utilizing the quick traverse function of the new water boxes, change time between product cycles was reduced, for an average savings of 60 minutes per week.

Overall product quality was improved by having a more uniform temperature control with a tolerance $+/-10^{\circ} \mathrm{C}$ after the project, compared to $+/-20^{\circ} \mathrm{C}$ before the upgrade at the laying head and more uniform cooling on the coil cooling conveyor due to better laying pattern. In addition, the coil package was improved with reduced coil height in the reform tub, leading to a better compacted package. See Figure 6 for a comparison of coil heights (in $\mathrm{mm}$ ) for rod sizes $5.5 \mathrm{~mm}$ through $9.5 \mathrm{~mm}$ before and after the modernization. 


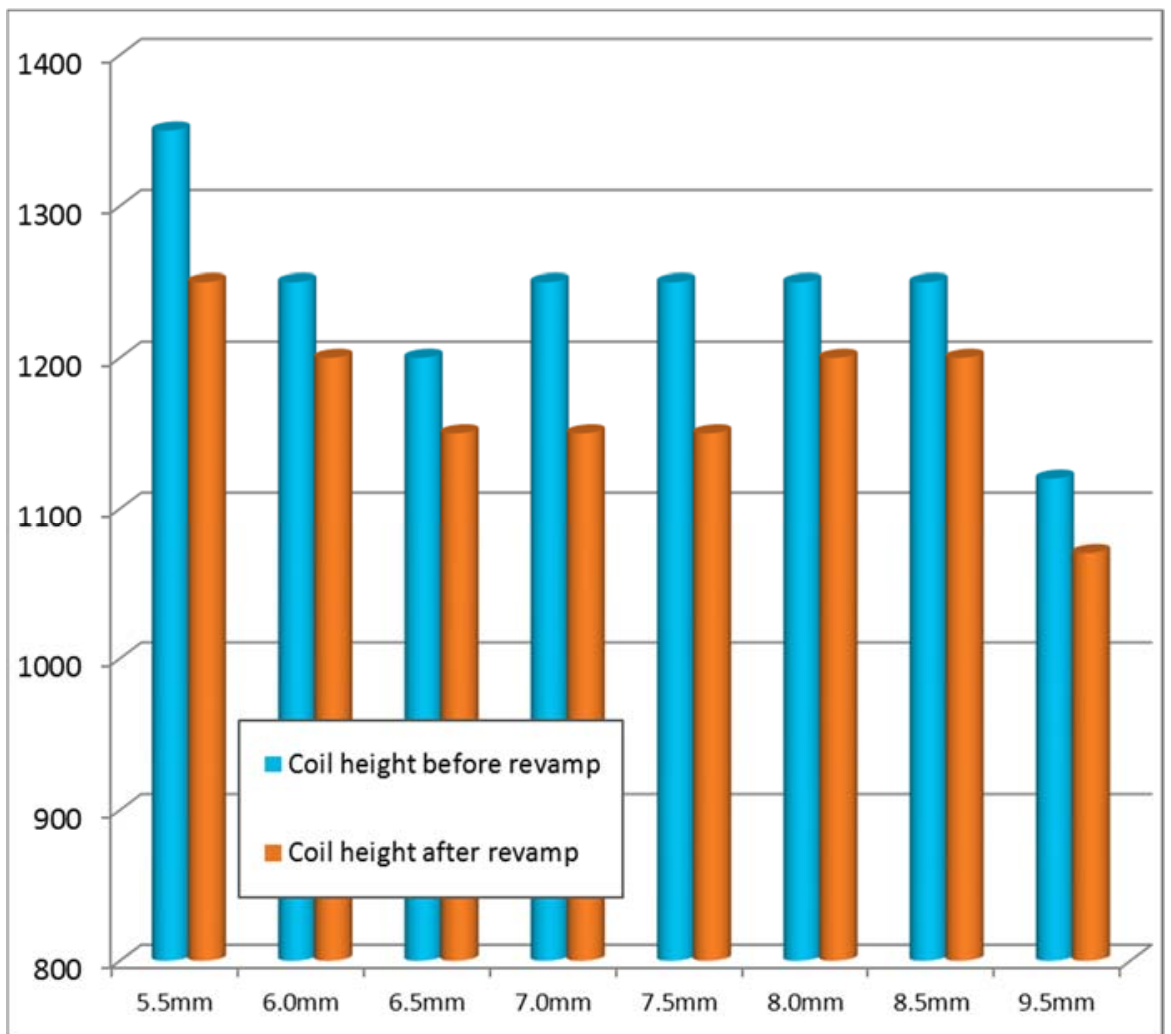

Figure 6 - Coil height reductions

The higher cooling capacity of the new water box system enabled lower laying head temperatures, which directly benefitted the scale conditions on the finished rod. Downstream users of the rod have reported on average a $35 \%$ decrease in scale losses in their operations.

\section{CONCLUSION}

The modernization undertaken by OneSteel in 2013 with Primetals Technologies achieved a number of quality and production goals, from an improved and expanded product mix to faster speeds and greater mill utilization. The goals were met thanks to a carefully designed layout and equipment selection that addressed OneSteel's specific challenges.

\section{REFERENCES}

1 Lashua CD and Kiefer BV. Recent Developments in Laying Head Technology for High Speed Rod Rolling Mills. Proceedings, AISTech 2014, Indianapolis, IN, USA, 2014. SR Series is a registered trademark of Primetals Technologies USA LLC 